Emin Aghayev

Kathrin Yen

Martin Sonnenschein

Christoph Ozdoba

Michael Thali

Christian Jackowski

Richard Dirnhofer

\title{
Virtopsy post-mortem multi-slice computed tomograhy (MSCT) and magnetic resonance imaging (MRI) demonstrating descending tonsillar herniation: comparison to clinical studies
}

Received: 6 November 2003

Accepted: 29 March 2004

Published online: 4 June 2004

(c) Springer-Verlag 2004

Supported by a grant from the Gerbert Ruef Foundation, Switzerland.

E. Aghayev $(\bowtie) \cdot K$. Yen $\cdot$ M. Thali

C. Jackowski $\cdot$ R. Dirnhofer

Institute of Forensic Medicine,

University of Bern, IRM-Buehlstrasse 20

3012 Bern, Switzerland

E-mail: emin.aghayev@irm.unibe.ch

Tel.: + 41-31-6318411

Fax: + 41-31-6318415

M. Sonnenschein

Institute of Diagnostic Radiology,

Inselspital, 3010 Bern, Switzerland

C. Ozdoba

Department of Neuroradiology,

Inselspital, 3010 Bern, Switzerland

\begin{abstract}
Descending cerebellar tonsillar herniation is a serious and common complication of intracranial mass lesions. We documented three cases of fatal blunt head injury using post-mortem multi-slice computed tomography (MSCT) and magnetic resonance imaging (MRI). The results showed massive bone and soft-tissue injuries of the head and signs of high intracranial pressure with herniation of the cerebellar tonsils. The diagnosis of tonsillar herniation by post-mortem radiological examination was performed prior to autopsy. This paper describes the detailed retrospective evaluation of the position of the cerebellar tonsils in post-mortem
\end{abstract}

imaging in comparison to clinical studies.

Keywords Virtopsy · Tonsillar herniation - Magnetic resonance imaging $\cdot$ Computed tomography . Forensic radiology $\cdot$ Post mortem

\section{Introduction}

Brain herniation is the mechanical displacement of brain, cerebrospinal fluid, and blood vessels outside the compartments in the head that they normally occupy. This occurs when pressure inside the skull (intracranial pressure) increases and displaces brain tissue. Usually, this is caused by space-occupying lesions such as primary or metastatic brain tumour, haemorrhage, or stroke that produce swelling of the brain, but it can also be found in head injury. Brain herniation itself often causes massive stroke resulting from poor blood supply to some areas of the brain and compression of vital structures that compromise cardiovascular and respiratory centres. This can rapidly lead to death or brain death. Once herniation in the brain's temporal lobe or the cerebellum occurs, death is often inevitable. Herniation of other brain areas has a variable prognosis [1].

Traditionally, diagnosis of the atrium mortis brain in autopsy is established on the basis of macro- or microscopical findings of brain injuries or pathology. Combined computed tomography (CT) and magnetic resonance imaging (MRI) is a new method suitable for post-mortem analysis of brain injuries and pathology [2, $3,4]$.

We report three cases of tonsillar herniation due to blunt head injury documented by post-mortem multislice computed tomography (MSCT) and MRI. The radiological diagnosis of herniated tonsils was performed prior to autopsy, but a retrospective comparison of autopsy findings and clinical studies was carried out. 


\section{Material and methods}

Radiological and autopsy examination

For imaging studies, bodies were wrapped in two radiological artefact-free body bags (Rudolf Egli A.G., Bern, Switzerland). In all three cases, MSCT was performed. CT scanning was performed on a GE Lightspeed QX/I unit (General Electric, Milwaukee, WI, USA). Slice thickness was $1.25 \mathrm{~mm}$; about 900 axial cross-sections were acquired. Sagittal and coronal reformations were calculated on a dedicated workstation (Advantage Windows 4.1, General Electric). The duration of each MSCT scan was about $10 \mathrm{~min}$.

MRI was performed in only two cases. MRI scanning was performed on a GE 1.5 T Signa Echospeed Horizon, version 5.8 unit (General Electric). T1-weighted spin-echo-series (TR/TE 400/14 ms) and T2-weighted fast-spin-echo-series (TR/TE 4000/105 ms) were acquired. In addition, axial and coronal $\mathrm{T} 2$-weighted images (TR/TE 4000/105 ms) were obtained. Imaging was performed using a head coil and a 4- to $10-\mathrm{mm}$ thick slice. MRI studies required approximately $2 \mathrm{~h}$. All measurements of the position of the cerebellar tonsils were performed on a workstation (Advantage Windows 4.1). Image interpretation was performed by board-certified neuroradiologists. Autopsy was performed by board-certified forensic pathologists. MSCT, MRI and autopsy results were compared.

\section{Case studies}

Case 1

A 72-year-old Caucasian man was struck by a motor vehicle while riding a bicycle. He was loaded on the hood of the car and he struck his head against the car roof girder. The impact point of the head was the occiput. The man wore no protective helmet. After the accident, he was transported to a tertiary care centre. Burr-hole trepanation of the skull was carried out, and a ventricle probe was inserted. The man remained unconscious and died $21 \mathrm{~h}$ after the accident. High intracranial pressure and brain oedema were considered as the cause of death. CT was performed $6 \mathrm{~h}$ post mortem, and an autopsy was carried out $24 \mathrm{~h}$ after death.

Case 2

A 22-year-old Caucasian man was struck by a motor vehicle while crossing a street. He was accelerated forwards and struck his head on the tarmac. The impact point of the head was the occiput. He was unconscious after the accident, and he was immediately taken to a tertiary care centre. The man died $9 \mathrm{~h}$ after the accident due to high intracranial pressure and brain oedema. CT and MRI were both performed $24 \mathrm{~h}$ post mortem, and an autopsy was carried out $38 \mathrm{~h}$ after death.

\section{Case 3}

An 87-year-old Caucasian woman fell down two steps. She struck her head on the floor. The impact point was the left temporal side of the skull. She was comatose after the accident and died $3 \mathrm{~h}$ later in the emergency room of a tertiary care centre. Clinical diagnoses were intracranial haematoma and beginning tonsillar herniation. CT and MRI were performed $6 \mathrm{~h}$ post mortem, and autopsy was carried out $20 \mathrm{~h}$ after death.

\section{Results}

\section{Radiological examination}

The radiological diagnosis of tonsillar herniation was made prior to the autopsy. A detailed retrospective evaluation of post-mortem imaging of cerebellar tonsils was carried out. For evaluating tonsillar position, the level of the foramen magnum was defined as a line from the inferior tip of the clivus (basion) to the inferior border of the posterior lip of foramen magnum (opisthion) [5]. The tonsils were most clearly demonstrated in the sagittal plane on reformatted CT images or on T2weighted MRIs (Figs. 1, 2, 3, and 4). The definition of opisthion and basion in MSCT examination was not complicated because of the high density of bone. In MRI, the opisthion was identified as the lowest point of intensity of cortical bone of the subocciput and the basion as the lowest point of low intensity of cortical bone of the clivus. When there was a discrepancy in position between the two tonsils, the level of the lower one was used for evaluation.

\section{Case 1}

CT showed a bent fracture of the occiput and a ring fracture of the base of the skull, which both corresponded to one impact point in the occiput. Above this fracture, subcutaneous occipital haematoma was seen; below, massive sub-dural and subarachnoid haemorrhage over both cerebral hemispheres and minor haemorrhage along the cerebellum were detected. Deep direct and contrecoup brain lesions and fractures of the roof of both orbits were also documented. A laceration of the left cerebellar hemisphere was observed. Mid-line shift towards the left side as a sign of the expanding intracranial masses and brain swelling was present. CT 
Fig. 1a,b Position of the left cerebellar tonsil in case 1 on sagittal plane of reformatted computed tomography $(\mathrm{CT})$ image. Measurement of the position composed $5.5 \mathrm{~mm}$ below the foramen magnum line. a Whole brain, b enlarged foramen magnum
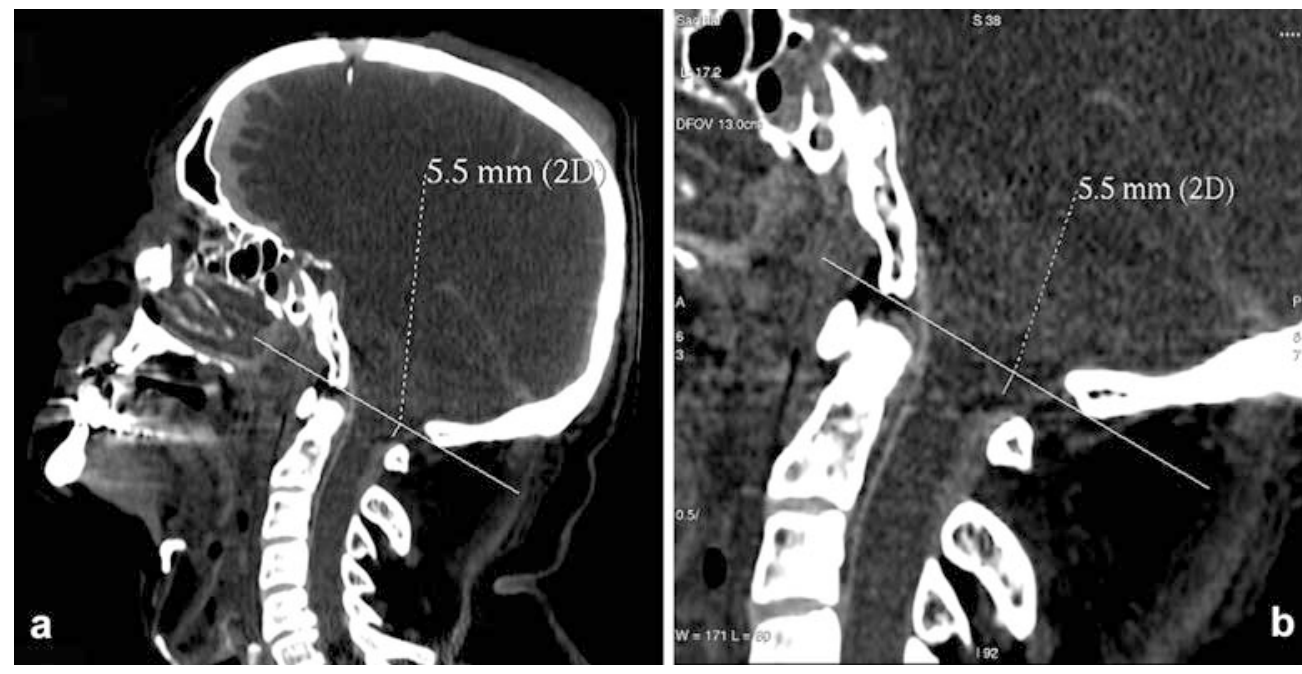

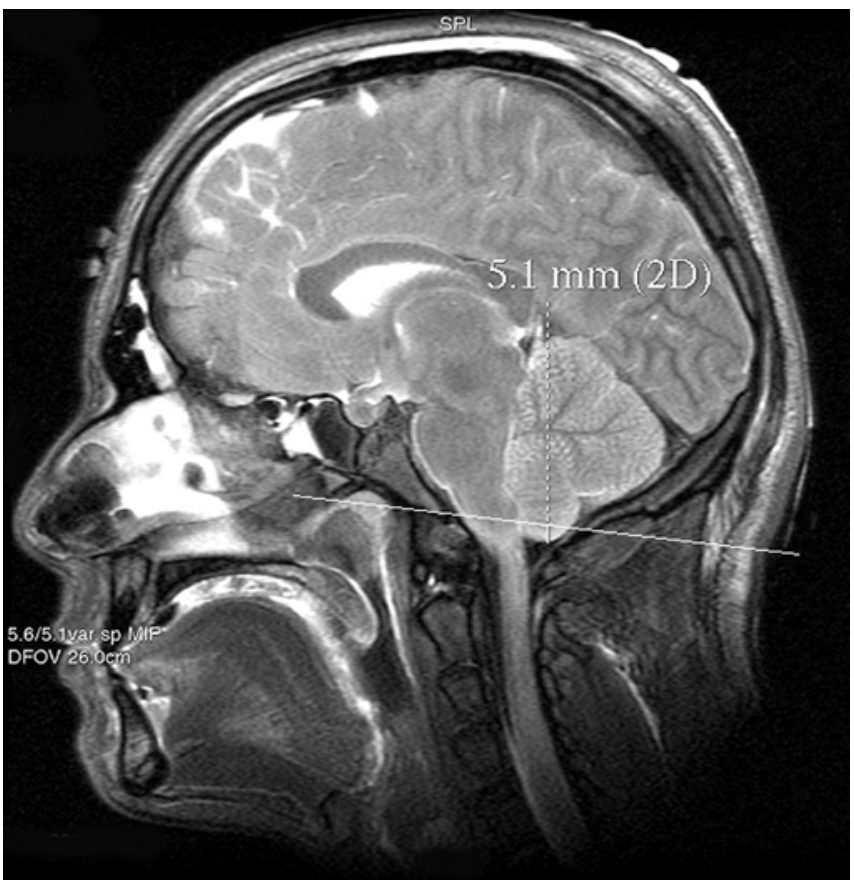

Fig. 2 Position of left cerebellar tonsil in case 2 on sagittal plane of T2-weighted magnetic resonance imaging (MRI). Measurement of the position composed $5.1 \mathrm{~mm}$ below the foramen magnum line

showed the swelling of the cerebellum, especially on the left side, with tonsillar herniation into the foramen magnum. Displacement of the tonsils on sagittal CT images was $5.5 \mathrm{~mm}$ below the foramen magnum line (Fig. 1).

\section{Case 2}

Radiological examination of the head showed an extended comminuted fracture of the base of the skull, which began at the right occiput and extended into the

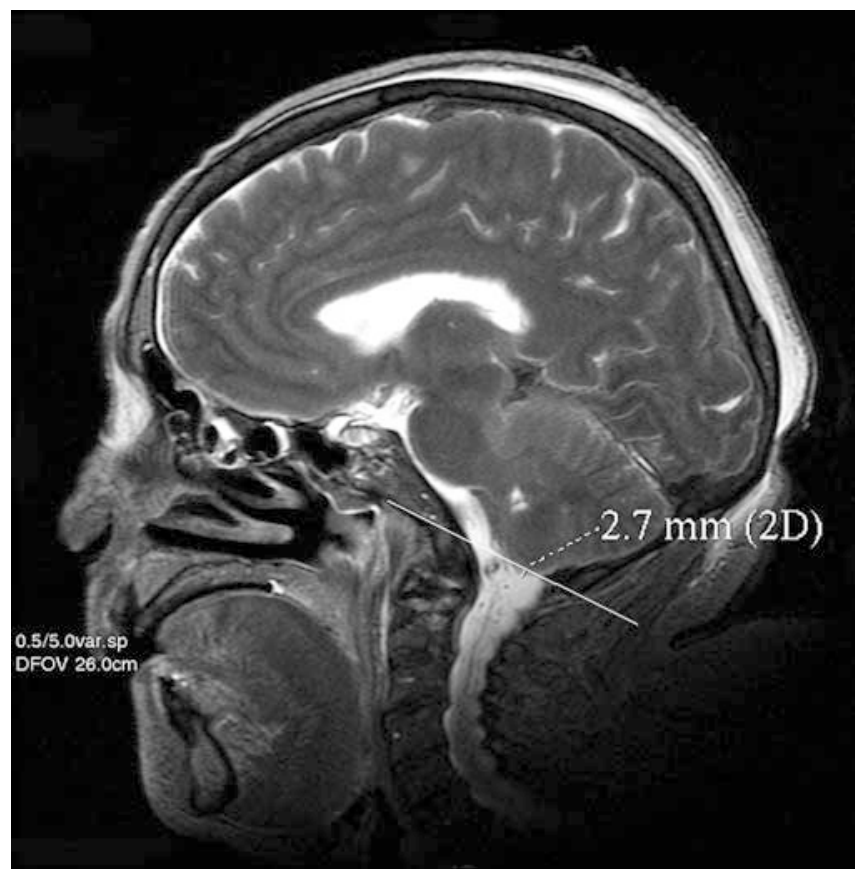

Fig. 3 Position of the tonsils in case 3 on sagittal plane of T2weighted magnetic resonance imaging (MRI). Measurement of the position composed $2.7 \mathrm{~mm}$ below the foramen magnum line

contralateral sella turcica. Haemorrhage into the subcutaneous fat tissue above and subdural and subarachnoidal haemorrhage below this fracture were detected. Deep direct and contrecoup brain bruises as well as the laceration of the left and contusion on the right cerebellar hemisphere were diagnosed. CT and MRI showed brain oedema and especially swelling of the cerebellum with herniated tonsils into the foramen magnum (Figs. 2 and 5). Displacement of the tonsils on the sagittal plane on T2- weighted MRIs was $5.1 \mathrm{~mm}$ below the foramen magnum line (Fig. 2). The position 
Fig. 4a,b Position of the tonsils in case 3 on sagittal plane of reformatted computed tomography $(\mathrm{CT})$ image. The measurement of the position composed same level as on magnetic resonance imaging (MRI_examination $2.7 \mathrm{~mm}$ below the foramen magnum line. a Whole brain, b enlarged foramen magnum
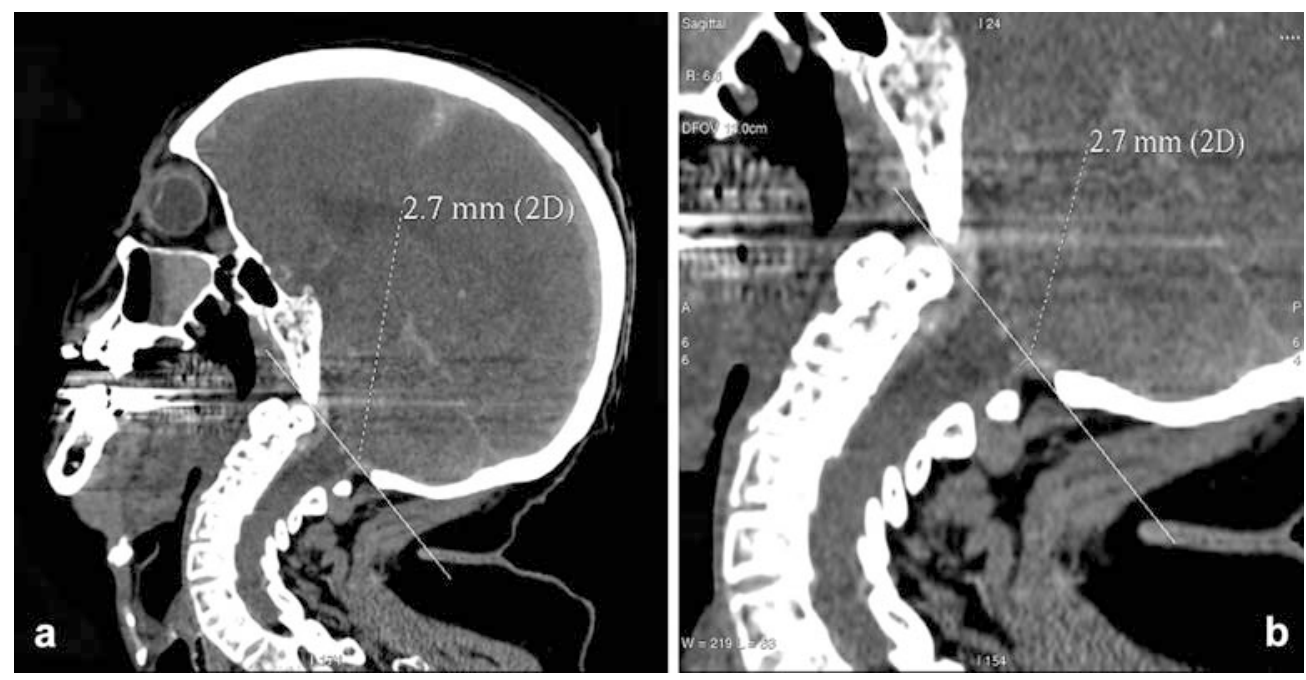

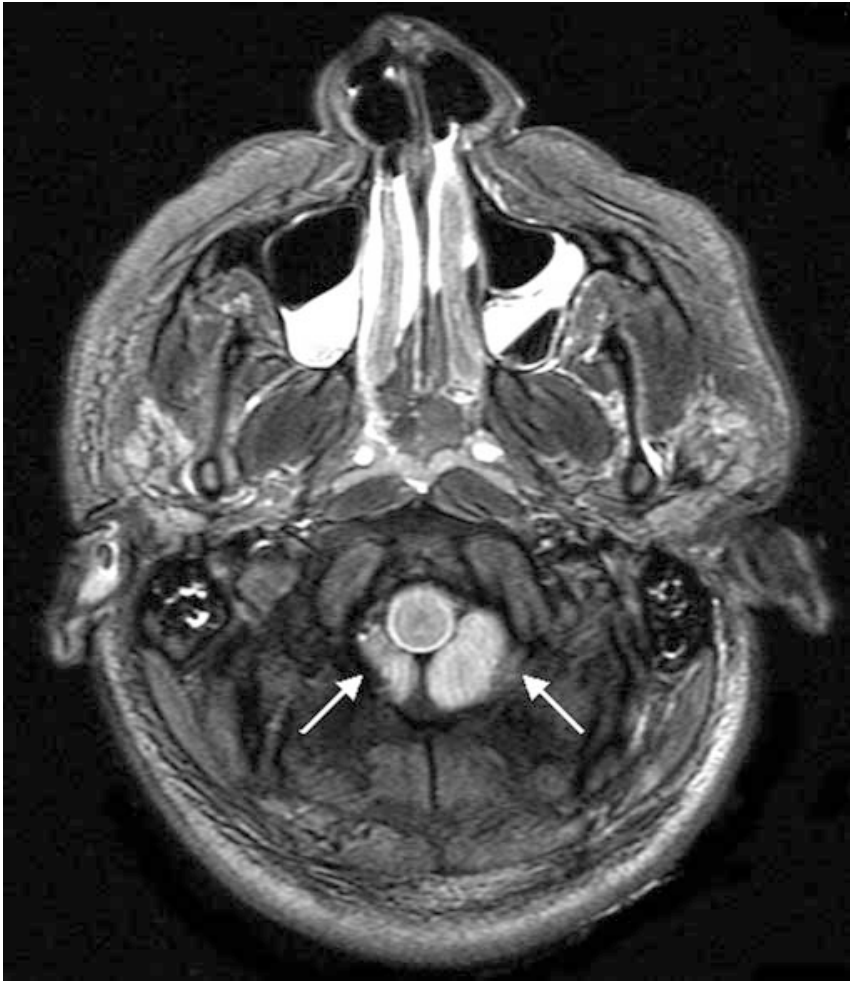

Fig. 5 Extensively symmetric axial plane of T2-weighted magnetic resonance imaging (MRI) just under the foramen magnum. Predominant herniation of the left cerebellar tonsil in case 2 (arrows)

of the tonsils on sagittal reformatted CT images could not be determined because of artefacts.

\section{Case 3}

CT showed a spider-web fracture of the left temporal skull with prolongation of the fracture line into the base of the skull up to the sella turcica. Massive subdural haematoma over both hemispheres with mid-line shift to the right was found. Temporo-basal contusions were seen in MRI. Haematocephalous and blood over the brain stem were diagnosed. CT and MRI detected massive swelling of the cerebrum and cerebellum with impending tonsillar herniation. On sagittal T2-weighted MRIs and reformatted CT images, the tonsils were found $2.7 \mathrm{~mm}$ below the foramen magnum line (Figs. 3 and 4).

\section{Autopsy}

Autopsy confirmed the above-mentioned radiological findings in all cases and, in this way, the diagnosis of tonsillar herniation was confirmed (Figs. 6 and 7). No additional relevant findings were discovered.

\section{Discussion}

Contusion and laceration of brain tissue results in rapid swelling. Swelling of the brain is common after substantial head injury. Although it is an almost inevitable accompaniment of almost all intracerebral damage as either a local or general phenomenon, it can occur as the sole abnormality and not infrequently proves fatal, particularly in young victims [6]. Oedema is the most common cause of elevated intracranial pressure. Another common space-occupying lesion, being seen less frequently than oedema, is intracranial or intracerebral haematoma. The presence of both space-occupying factors increases the gravity of the injury and in our three cases proved fatal.

Anatomically, tonsillar herniation is defined as displacement of the cerebellar tonsils downwards through the foramen magnum into the cervical canal. 


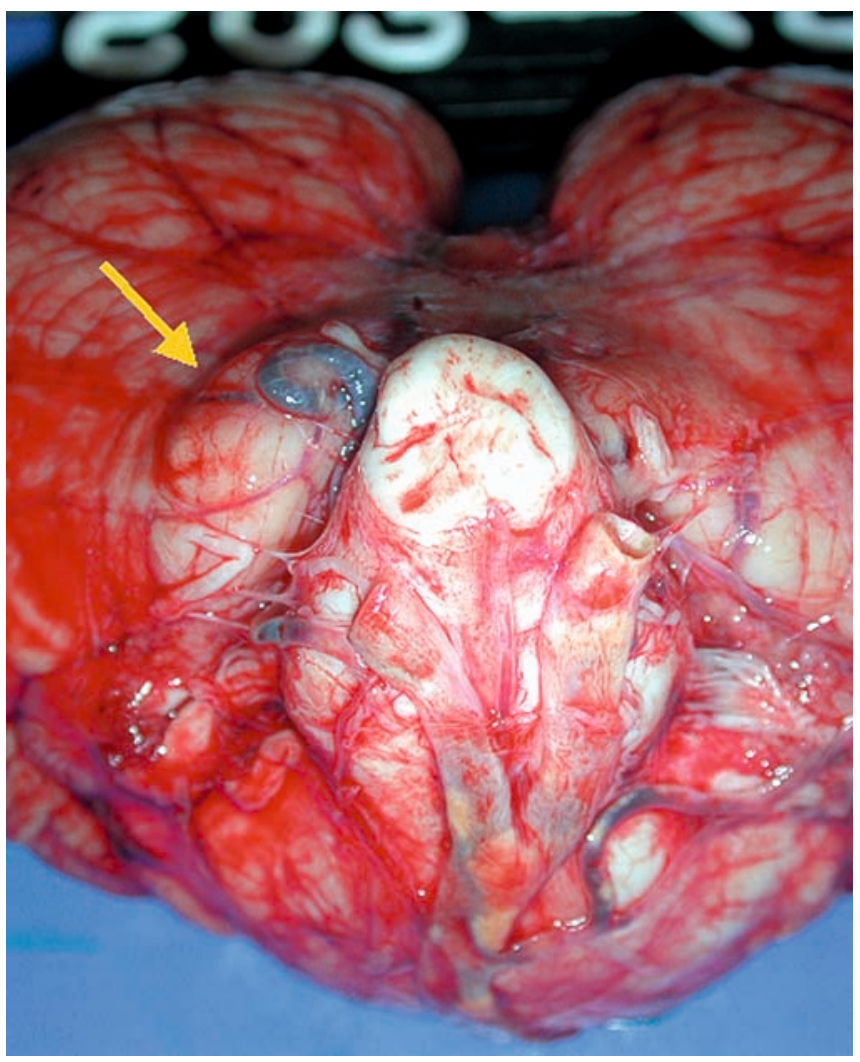

Fig. 6 Predominant swelling of the left cerebellar tonsil in case 1 in autopsy (arrow)

Predominantly, unilateral swelling and cerebellar herniation in cases 1 and 2 is explained by the unilateral laceration of the cerebellum (Fig. 7). Detection of tonsillar herniation in clinical MRI and MSCT examina- tions was reported previously. On myelograms, O'Connor et al. reported that the cerebellar tonsils were at least $3.8 \mathrm{~mm}$ higher than the line of the foramen magnum in all of a series of 100 normal cases [7]. Using T1-weighted sagittal MRIs, however, Barkovich et al. reported that the position of the tonsils ranged from $8 \mathrm{~mm}$ above to $5 \mathrm{~mm}$ below the foramen magnum in normal subjects and that less than $2 \mathrm{~mm}$ of tonsillar displacement on MRI would be of no clinical significance [8]. Ishikawa et al. noted tonsillar displacement below the foramen magnum line in only three from a total of 18 cases of posterior fossa mass lesions [5].

We studied three cases of fatal blunt head injury. The post-mortem CT and MRI studies demonstrated tonsillar herniation. The position of the tonsils in our cases was $5.5 \mathrm{~mm}, 5.1 \mathrm{~mm}$, and $2.7 \mathrm{~mm}$ below the foramen magnum line. The tonsils were most clearly demonstrated in the sagittal plane on T2-weighted MRIs.

Most authors recommend MRI for the diagnosis of tonsillar herniation in vivo $[5,7,8,9,10]$. The demonstration of descending brain herniation in the foramen magnum with CT is often difficult mostly because of bony artefacts and partial volume effects [5]. The resolution of tonsillar herniation in MRI is superior to CT. MSCT and MRI used post mortem are comparatively young examination methods in forensic medicine $[2,3,4$, $11,12,13]$. The sensitivity of MRI and CT to discover signs of high intracranial pressure such as tonsillar herniation in clinical medicine is already known from the work of Barkovich [5], Ishikawa [8] and Reich [9]. Today, CT and MRI have become indispensable in the clinical diagnostic of head injury $[5,7,8,9,10]$. Our results show that these methods are also sensitive in the
Fig. 7 Predominant swelling of the left side of the cerebellum in case 2. Impressed furrow caused by occipital bone on the left tonsil after fixation in formalin during 1 week (thick arrow). Laceration of the left cerebellar hemisphere (dotted arrow) and subarachnoidal haematoma on the right cerebellar hemisphere (thin arrow)

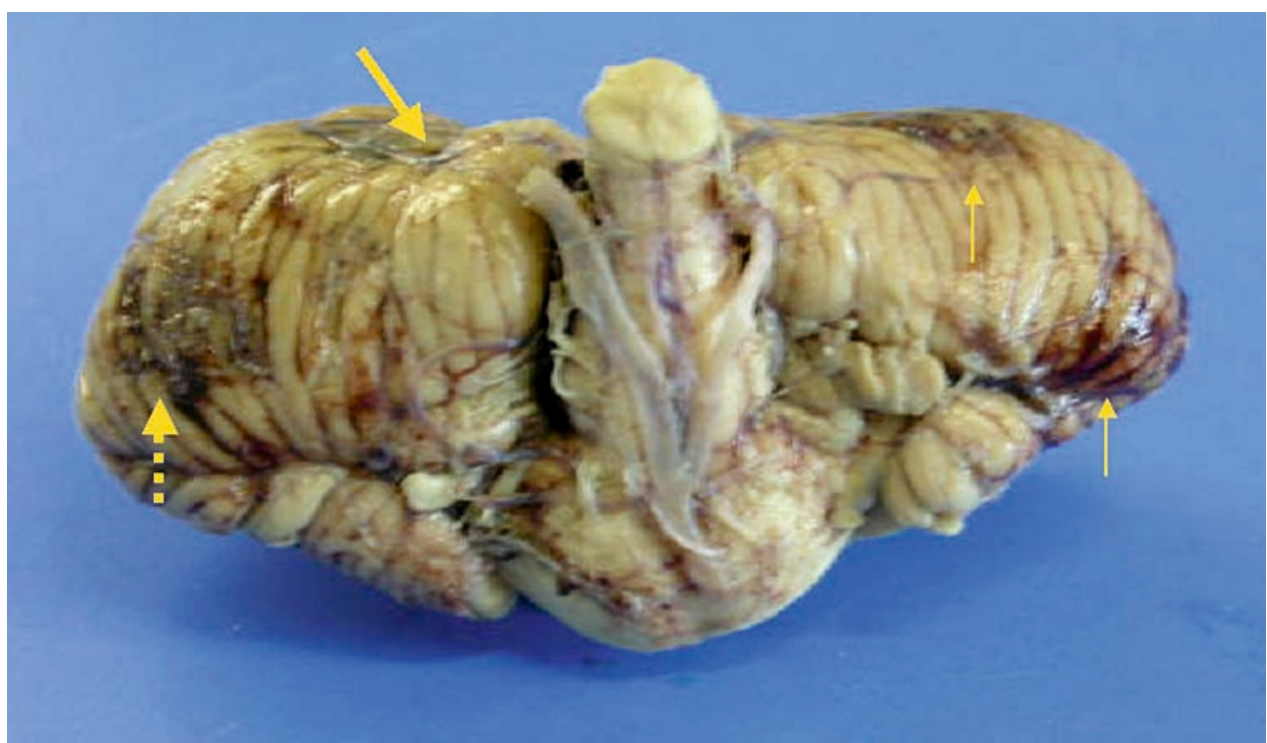


post-mortem diagnostics of descending tonsillar herniation.

Acknowledgements We are grateful to Karin Zwygart and Elke Spielvogel (Departments of Diagnostic Radiology and Neurora- diology, University Hospital of Bern) and to Roland Dorn and Urs Koenigsdorfer (Institute of Forensic Medicine, University of Bern) for the excellent help in data acquisition during the radiologic examination and the forensic autopsy.

\section{References}

1. Medline Plus (2003) Medical encyclopedia,http://www.nlm.nih.gov/medlineplus/ency/article/001421.htm. Cited 20 Nov 2003

2. Thali MJ, Yen K, Schweitzer W, Vock P, Boesch C, Ozdoba C, Schroth G, Ith $\mathrm{M}$, Sonnenschein M, Doernhoefer T, Scheurer E, Plattner T, Dirnhofer R (2003) Virtopsy, a new imaging horizon in forensic pathology: virtual autopsy by post-mortem multislice computed tomography (MSCT) and magnetic resonance imaging (MRI)-a feasibility study. J Forensic Sci 48:386-403

3. Thali MJ, Yen K, Plattner T, Schweitzer W, Vock P, Ozdoba C, Dirnhofer R (2002) Charred body: virtual autopsy with multi-slice computed tomography and magnetic resonance imaging. J Forensic Sci 47:1326-1331
4. Thali MJ, Yen K, Schweitzer W, Vock P, Ozdoba C, Dirnhofer R (2003) Into the decomposed body-forensic digital autopsy using multislice-computed tomography. Forensic Sci Int 134:109-114

5. Ishikawa M, Kikuchi H, Fujisawa I, Yonekawa Y (1988) Tonsillar herniation on magnetic resonance imaging. Neurosurgery 22:77-81

6. Knight B (1991) Head and spinal injuries. In: Knight B (ed) Forensic pathology. Arnold, London, pp 156-197

7. O'Connor S, du Boulay G, Logue V (1973) The normal position of the cerebellar tonsils as demonstrated by myelography. J Neurosurg 39:387-389

8. Barkovich AJ, Wippold FJ, Sherman JL, Citrin CM (1986) Significance of cerebellar tonsillar position on MR. Am J Neuroradiol 7:795-799

9. Reich JB, Sierra J, Camp W, Zanzonico P, Deck MD, Plum F (1993) Magnetic resonance imaging measurements and clinical changes accompanying transtentorial and foramen magnum brain herniation. Ann Neurol 33:159-170
10. Greenberg JO (1984) Neuroimaging in brain swelling. Neurol Clin 2:677-694

11. Thali MJ, Schwab CM, Tairi K, Dirnhofer R, Vock P (2002) Forensic radiology with cross-section modalities: spiral CT evaluation of a knife wound to the aorta. J Forensic Sci 47:10411045

12. Thali MJ, Schweitzer W, Yen K, Vock P, Ozdoba C, Spielvogel E, Dirnhofer R (2003) New horizons in forensic radiology:the 60-second digital autopsy-full-body examination of a gunshot victim by multislice computed tomography. Am J Forensic Med Pathol 24:22-27

13. Thali M, Vock P (2003) Role of and Techniques in Forensic Imaging. In: Payen-James J, Busuttil A, Smock W (eds) Forensic medicine: clinical and pathological aspects. Greenwich Medical Media, London, pp 731-745 